\begin{tabular}{|lc|}
\hline Abstract PO-0286 Table 1 & \\
\hline \multicolumn{1}{|c|}{ Interventions } & Percentage $\%$ \\
\hline Intubated by AT & $86 \%$ \\
\hline Intubated by NWTS & $11.1 \%$ \\
\hline Intubated by COCH Neonatal team & $2.7 \%$ \\
\hline Nasal intubations by COCH & $22.5 \%$ \\
\hline Endotracheal tube (ET) repositioned by NWTS & $16.1 \%$ \\
\hline ET repositioned by AT & $6.4 \%$ \\
\hline Central venous lines by COCH & $43 \%$ \\
\hline Central venous lines by NWTS & $57 \%$ \\
\hline
\end{tabular}

\section{P0-0286 ROLE OF THE ANAESTHETIC TEAM IN PAEDIATRIC CRITICAL CARE TRANSFERS IN THE NORTH WEST OF UK}

${ }^{1} \mathrm{G}$ Sefton, ${ }^{2} \mathrm{NK}$ Puppala, ${ }^{3} \mathrm{R}$ Phatak, ${ }^{2} \mathrm{~N}$ Campbell. 'Alder Hey Children's NHS Foundation Trust, Liverpool, UK; ${ }^{2}$ Anaesthesia, Countess of Chester Hospital NHS Foundation Trust, Chester, UK; ${ }^{3}$ Paediatric Intensive Care, North West and North Wales Paediatric Transport Service, Warrington, UK

\subsection{6/archdischild-2014-307384.938}

Background and aims Critically ill children in the UK are stabilised in the district general hospitals (DGH) and transferred to tertiary paediatric intensive care units (PICU). The North West and North Wales Paediatric transport Service (NWTS) is a specialist paediatric retrieval service, which transports sick children and also provides expert advice to DGH staff. However, in the DGHs, anaesthetic teams (AT) provide the initial resuscitation and undertake the time-critical transfers. Countess of Chester hospital $(\mathrm{COCH})$ is one of the 29 DGHs in the north-west. The aim of this project was to review the role of AT in resuscitation, stabilisation and transfer of critically ill children from $\mathrm{COCH}$ to PICUs.

Methods Retrospective review of patient notes, NWTS- transport documentation and discharge summaries of the patients at tertiary PICUs over 2.5 years between November 2010 to August 2013.

Results Of the 43 transfers from COCH 11 transfers were undertaken by AT. Major proportion of interventions were performed by the AT and the NWTS stabilisation time at $\mathrm{COCH}$ was similar to that in the rest of the DGHs. (See Table and Figure).

Stabilisation Times (ST in mins) by NWTS at COCH vs ST in mins by NWTS for the rest of the north west

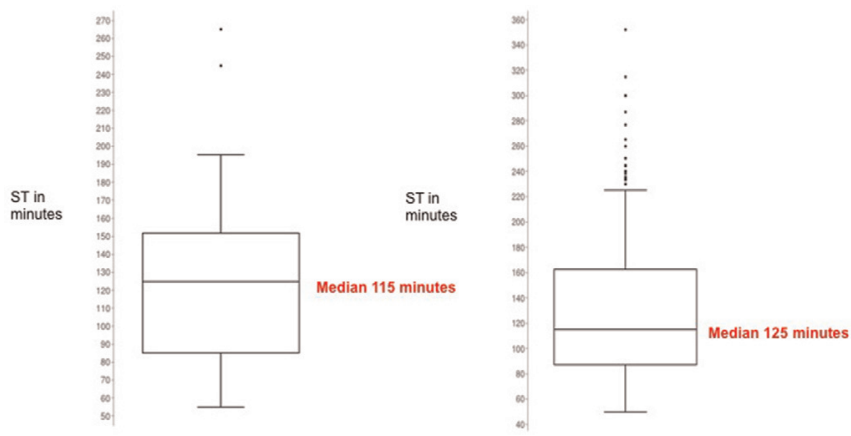

Abstract PO-0286 Figure 1
Conclusions Anaesthetic teams at DGH play a significant role in the resuscitation, stabilisation and transfer of critically ill children. Effective communication with the transport service and shared protocols enhance the performance of the DGH staff.

\section{PO-0287 PAEDIATRIC EMERGENCY DEPARTMENT VISITS ON A LEVEL II HOSPITAL IN PORTUGAL}

${ }^{1}$ M Rafael, ${ }^{2} \mathrm{SL}$ Portela, ${ }^{3} \mathrm{P}$ Sousa, ${ }^{3} \mathrm{AC}$ Fernandes. ${ }^{1}$ Pediatria, Centro Hospitalar BarreiroMontijo, Barreiro, Portugal; ${ }^{2}$ Métodos Quantitativos, Iscte-Iul, Lisboa, Portugal; ${ }^{3}$ Politicas E Administração de Saúde, Escola Nacional de Saúde Pública, Lisboa, Portugal

\subsection{6/archdischild-2014-307384.939}

Background and aims Nowadays in Portugal we are witnessing an excessive demand for differentiated health services which generates misuse of resources, increase in costs and a tendency of rupture to the system itself. We aimed to characterise a paediatric emergency department (PED)'s use and to define whether there is unjustified demand for health care.

Methods Retrospective cross sectional analysis of emergency episodes during one year (2012) on a level II PED in Barreiro, Portugal. Episodes were defined as unjustified when classified as standard and non-urgent by Manchester Triage. Demographic and clinical data were analysed. Adequate statistical analysis was performed; level of significance $\mathrm{p}<0.05$.

Results We analysed 37,099 PED episodes. Most patients were male (53\%), and There was a significant correlation between PED's unjustified use and both week's day and day's hour: episodes occurred mostly at weekends ( $\mathrm{p} 11$-years $(\mathrm{p}<0.05)$.

Conclusion There was an excessive use of the PED by nonemergent episodes in our study. It's crucial to create measures to contain this phenomenon, namely promoting and strengthening the primary health care, the chain of care and referral network, as well as increase the population's health literacy.

\section{P0-0288 HYPERFERRITINEMIA IN MANAGING PERINATAL HEMOCHROMATOSIS: POSITIVE PREDICTIVE VALUE AND EFFECTIVENESS}

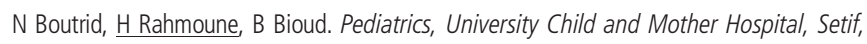
Algeria

\subsection{6/archdischild-2014-307384.940}

Introduction Ferritin is commonly used to estimate iron stores but its strength also can diagnose rarer and more severe pathologies and then guide the emergency treatment

Material and method A little girl of 45 days is admitted for pallor, fatigue and failure to gain weight. Laboratory tests reveal a rapidly worsening hepatitis with growing signs of liver failure. Her Alpha -fetoprotein is 64,000 IU while serum ferritin $>2000$ $\mathrm{ng} / \mathrm{ml}$. The most likely diagnosis, neonatal hemochromatosis, required to initiate combination therapy with vitamin $\mathrm{E}$ and $\mathrm{N}$ acetylcysteine, NAC. After 2 months of treatment, there are no more stigmata of liver failure; AFP is $3200 \mathrm{IU}$ and ferritin = $632 \mathrm{ng} / \mathrm{ml}$.

Results and discussion This case illustrate, among others, the outstanding interests of ferritin dosage in such situations with high morbidity/mortality, requiring a battery of specialised explorations that are not always accessible in ressource limited areas.

In fact, iron overload is characteristic of this immune-mediated condition with specific MRI findings in salivary glands and liver. 